\title{
Biologic-like in vivo Efficacy with Small Molecule Inhibitors of TNF $\alpha$ Identified Using Scaffold Hopping and Structure-Based Drug Design (SBDD) Approaches
}

Hai-Yun Xiao, * Ning Li, James J.-W. Duan, Bin Jiang, Zhonghui Lu, Khehyong Ngu, Joseph Tino, Lisa M. Kopcho, Hao Lu, Jing Chen, Andrew J. Tebben, Steven Sheriff, ChiehYing Y. Chang, Joseph Yanchunas Jr., Deepa Calambur, Mian Gao, David J. Shuster, Vojkan Susulic, Jenny H. Xie, Victor R. Guarino, Dauh-Rurng Wu, Kurt R. Gregor, Christine B. Goldstine, John Hynes Jr., John E. Macor, Luisa Salter-Cid, James R. Burke, Patrick J. Shaw and T. G. Murali Dhar*

Research and Early Development, Bristol Myers Squibb, 3551 Lawrenceville Rd, Princeton, New Jersey 08540, United States.

\section{Supporting Information}

Mouse TNF $\alpha$ induced PK/PD model $\quad$ S2

Collagen Antibody-Induced arthritis model (CAIA) S3

$\begin{array}{ll}\text { E-Selectin assay protocol } & \text { S4 }\end{array}$

Protein expression, purification and crystallization, X-ray crystal

$\begin{array}{ll}\text { structure data collection and structure refinement } & \text { S5-S8 }\end{array}$

$\begin{array}{ll}\text { Analytical data for representative compounds } & \text { S9-S15 }\end{array}$ 
All the experiments involving animals have been performed in accordance with institutional guidelines as defined by the Institutional Animal Care and Use Committee for U.S. Institutions.

\section{Mouse TNF $\alpha$ induced PK/PD model.}

This study was performed to determine effect of program compound(s) on TNF -induced cytokines (in this case, IL-6) in mice. Serum IL-6 measurements were made by ELISA.

Group size: Female C57Bl/6 (Jackson) 6 to 8 per group. Mice should be at least 20 gram for use and should acclimate in house at least 2 weeks to reduce variability.

Compound $\mathbf{4 2}$ was dosed at 5 and $25 \mathrm{mg} / \mathrm{kg}$ PO, 1 hour before TNF challenge, while murine Enbrel (10 mg/kg) IP was given approximately 16 hours before TNF stimulation (evening before TNF challenge) as a positive control in this model. Two to three untreated mice (naïve) were included as baseline control.

Following administration of compound 42, Murine TNF (Cell Sciences Cat no CRT192C) was prepared fresh by reconstituting the lyophilized with $0.1 \%$ Bovine serum albumin (BSA) in sterile PBS, and then diluted appropriately in $0.1 \%$ BSA for preparation of $10 \mathrm{ug} / \mathrm{ml}$ IV dosing solution. $0.1 \mathrm{ml}$ was injected IV via the retro-orbital sinus. IV dosing performed under isoflurane anesthesia.

At 2 hours after TNF injection, a terminal blood collection was performed using the cardiac puncture method. Whole blood was used for PK measurement using the dried blood spot (DBS) matrix. The PK time point is 3 hours after compound administration. Blood was also collected for serum separation and used for cytokine analysis of mouse IL-6 by ELISA. 
All the experiments involving animals have been performed in accordance with institutional guidelines as defined by the Institutional Animal Care and Use Committee for U.S. Institutions.

\section{Collagen Antibody-Induced arthritis model (CAIA).}

In this arthritis model, a cocktail mixture of 4 monoclonal anti-mouse type II collagen antibodies (1 mg of each) was administered intraperitoneally (IP) to female BALB/c mice (Envigo; 8-10 weeks old). Three days later, the mice were injected IP with 10ug of lipopolysaccharide (E. coli O111:B4, Sigma).

PO dosing with compound $\mathbf{4 2}$ and placebo was immediately started 6 hours after LPS challenge. Compound 42 was administered PO, BID at $2 \mathrm{mg} / \mathrm{kg}$ and $10 \mathrm{mg} / \mathrm{kg}$ daily. The placebo group received the same dosing regimen with blank formulation vehicle (90:5:5 PEG 400:TPGS:Ethanol). Since it was BID dosing, the dose volume was reduced to $5 \mathrm{~mL} / \mathrm{kg} /$ day. Mouse Enbrel (mTNFR1B-mFC-IgG2a) was formulated in PBS and dosed at $10 \mathrm{mg} / \mathrm{kg}$, SC, twice a week as a positive control.

Mice were monitored daily, starting on Day 4, for development and severity of paw inflammation. Paws were evaluated visually and scored based on the severity of inflammation/swelling of the digits and paws. Clinical score was based on the following numbering system: (1) 1 or more swollen digits per paw; (2) Mild paw swelling; (3) Moderate paw swelling (4) Fusion of joints/ankylosis, with a possible maximum score of 16 per mouse.

Takedown was on day 12 when the mice were euthanized. Samples were collected for trough PK. In addition, paws were collected for RT-PCR. 


\section{Experimental protocol for the E-selectin assay.}

Materials:

HUVEC cells were purchased from ATCC (Manassas, VA), maintained and propagated in EGM-2 formulated BulletKit growth media (Lonza), and expanded to confluence at $37^{\circ} \mathrm{C}$ in a humidified incubator with 5\% $\mathrm{CO}_{2}$. HUVEC cells were distributed to 96-well plates for activation and flow cytometry.

For compound treatment and HUVEC activation, and to measure the pharmacological modulation of inhibitors on E-selectin expression, recombinant His-cleaved trimeric TNF $(0.5 \mathrm{ng} / \mathrm{ml}, 9.8 \mathrm{pM})$ was pretreated with a various doses of compound $42(0.66 \% \mathrm{DMSO})$ for 30 minutes before adding HUVEC cells $(50,000)$ to plates and activating cells for $3 \mathrm{hrs}$ at $37^{\circ} \mathrm{C}$. The TNF $\alpha$-dependent regulation of the expression of E-selectin, is known to signal through TNFR1. E-selectin expression by Flow Cytomtetry, prior to detachment from the wells with TrypsinEDTA (.05\%) Life Tech for 10 minutes at $37^{\circ} \mathrm{C}$, HUVEC cells were stained with E-selectin PE (1uL/well, Biolegend 322606, clone HCD62E) in 50ul FACS buffer for 30 minutes on ice and washed in PBS. Trypinized cells were resuspended in FACS buffer and the data acquired using the BD Canto cytometer. Gating on HUVEC cells, and measuring MFI (median fluorescent intensity) of CD62E-PE on HUVEC cells was used to calculate \% inhibition and $\mathrm{IC}_{50}$ 's against vehicle treated cells. 


\section{Protein expression, purification and crystallization, X-ray crystal structure data collection}

and structure refinement.

Soluble region of human TNFa (RefSeq NP_000585) containing amino acids 77-233 was cloned for expression as a His tagged protein into a pET-28 based plasmid construct. The expression plasmid was generated by PCR and cloned as NdeI-XhoI fragment into pET28- Nhis-TVMV which had been digested with the same enzymes. DNA sequence of the final construct was confirmed by sequencing.

To produce properly folded soluble protein with disulfide bonds, His-TVMV-hTNF $\alpha$ [77233] was expressed in E. coli SHuffle pLysY Express cells [New England Biolabs]. Transformed cells were grown at $30^{\circ} \mathrm{C}$ in $\mathrm{M} 9$ minimal media supplemented with casamino acids and trace minerals until an optical density of 0.8 at $600 \mathrm{~nm}$ was reached. Protein expression was induced by adding isopropyl -D-1-thiogalactopyranoside [Calbiochem] to a final concentration of 0.4mM. After 20 hour incubation at $16^{\circ} \mathrm{C}$, the cells were harvested by centrifugation and pelleted cells were stored at $80^{\circ} \mathrm{C}$ until protein purification.

Cell pellets were resuspended in buffer A [30mM Sodium Phosphate, $\mathrm{pH} 8.0 ; 0.5 \mathrm{M}$ $\mathrm{NaCl}$ ] containing 20mM Imidazole, complete EDTA free Protease inhibitor tablets [Roche Applied Science] and Benzonase [Sigma] and were lysed by high pressure homogenizer, Emulsiflex-C5, Avestin [1 pass at 10,000 psi]. The supernatant containing soluble hTNF $\alpha$ was clarified by centrifugation. The following were all performed at $4{ }^{\circ} \mathrm{C}$ on AKTA purifier system [GE Life Sciences]. The supernatant was loaded onto two $5 \mathrm{ml}$ HisTrap FF Crude columns connected in series (GE Healthcare Life Sciences) equilibrated with buffer A containing 20mM Imidazole. The column was washed sequentially with five column volumes of equilibration buffer and five column volumes of buffer A containing 40mM imidazole $\mathrm{pH}$ 8.0. The column 
was eluted with 5 column volumes of buffer A containing $500 \mathrm{mM}$ imidazole $\mathrm{pH}$ 8.0. The eluted protein was concentrated by centrifugal ultrafiltration to $10 \mathrm{ml}$ using Amicon Ultra-15 concentrators with a 10,000 Da cutoff. The retentate was loaded onto a HiLoad 26/600 Superdex 200 pg column (GE Healthcare Life Sciences) pre-equilibrated with buffer A. The fractions containing purified His-TVMV-hTNF $\alpha$ [77-233] protein were pooled. For assay support, the purified His-tagged protein was flash frozen and stored at $-80{ }^{\circ} \mathrm{C}$ in small aliquots. For crystallization experiments, the His tag was removed by digestion with purified, recombinant His-TVMV protease for $16 \mathrm{~h}$ at $4^{\circ} \mathrm{C}$ [1:10 ratio of TVMV protease:His-TVMV-hTNF [77-233]]. The His-TVMV protease and residual His tag were removed by loading the reaction mixture onto a $5 \mathrm{ml}$ column of Ni Sepharose 6 Fast Flow (GE Healthcare Life Sciences) pre-equilibrated with buffer A containing $25 \mathrm{mM}$ Imidazole. The column flowthrough fraction was concentrated and further purified by loading onto a HiLoad 16/600 Superdex 200 pg column equilibrated in $20 \mathrm{mM}$ Tris, $\mathrm{pH} 8.0 ; 0.1 \mathrm{M} \mathrm{NaCl}$. A final purity of $>95 \%$ was achieved, with a yield of $50 \mathrm{mg}$ per L cell culture. The cleaved hTNF $\alpha$ was concentrated to $20 \mathrm{mg} / \mathrm{ml}$, flash frozen in LN2 and stored at $-80^{\circ} \mathrm{C}$ in $3 \mathrm{mg}$ aliquots. Liquid chromatography/mass spectrometry confirmed the presence of cleaved-hTNF $\alpha$ (77-233) containing single di-sulfide bond. The association state as determined size exclusion chromatography with inline multiangle light scattering (SEC-MALS) data demonstrate that the cleaved hTNF $\alpha$ predominantly exists as the expected trimer.

Complex for co-crystallization studies was prepared as described in literature ${ }^{1,2}$. A frozen aliquot of cleaved $\mathrm{hTNF} \alpha$ at $\sim 1 \mathrm{mM}$ concentration $[20 \mathrm{mg} / \mathrm{ml}]$ was thawed and incubated with equimolar concentration of inhibitor. The complex was incubated overnight on ice and further concentrated to $\sim 33 \mathrm{mg} / \mathrm{ml}$. Co-crystals of TNF $\alpha$ with 16 were grown in $100 \mathrm{mM}$ HEPES, pH 7.5, 13\% (w/v) MEPEG5K, and 3\% (v/v) dioxane. The crystal was harvested in a solution 
consisting of the crystallization solution plus $25 \%$ (v/v) glycerol as a cryoprotectant. Data for the complex with 16 were collected using a Rigaku FR-E Superbright X-ray generator, Rigaku VariMax HF Arc)Sec confocal optics, and a Dectris Pilatus 200K. The diffraction data for TNF $\alpha$ in complex with 16 were processed with $\mathrm{XDS}^{3,4}$ and scaled with $\mathrm{AIMLESS}^{5}$ using autoPROC (GlobalPhasing, Ltd., Cambridge, UK). Our original structure of TNF $\alpha$ with a compound not reported here was determined by molecular replacement using PHASER ${ }^{6}$ with a model derived from chain A of PDB ID 2AZ5. The structure reported here was placed by rigid body only refinement using the $\mathrm{CCP} 4{ }^{7}$ version of $\mathrm{AMoRe}^{8}$. TNF $\alpha$ in complex with 16 was refined with BUSTER/TNT ${ }^{9}$ (GlobalPhasing, Ltd., Cambridge, UK), using GRADE (GlobalPhasing, Ltd., Cambridge, UK) to generate a restraint dictionary for 16, and using RHOFIT (GlobalPhasing, Ltd., Cambridge, UK) for initial placement of 16. COOT ${ }^{10}$ was used for model fitting.

\section{$\underline{\text { References }}$}

${ }^{1}$ He, M.M.; Smith, A.S.: Oslob, J.D.; Flanagan, W.M.; Braisted, A.C.; Whitty, A.; Cancilla, M.T.; Wang, J.; Lugovskoy, A.A.; Yoburn, J.C.; Fung, A.D.; Farrington, G.; Eldredge, J.K.; Day, E.S.; Cruz, L.A.; Cachero, T.G.; Miller, S.K.; Friedman, J.E.; Choong, I.C.; Cunningham, B.C. Small-Molecule Inhibition of TNF- $\alpha$. Science 2005, 310, $1022-1025$.

${ }^{2}$ Chan, D.S.-H.; Lee, H.-M.; Yang, F.; Che, C.-M.; Wong, C.C.L.; Abagyan, R., Leung, C.-H.; Dik-Lung Ma. StructureBased Discovery of Natural-Product-like TNF- $\alpha$ Inhibitors. Angew. Chem., Int. Ed 2010, 49, 2860-2864.

${ }^{3}$ Kabsch, W. XDS. Acta Crystallogr. Sect. D 2010, 66, 125-132.

${ }^{4}$ Kabsch, W. Integration, scaling, space-group assignment and post-refinement. Acta Crystallogr. Sect. D 2010, 66, 133144.

${ }^{5}$ Evans, P.R. \& Murshudov, G.N. How good are my data and what is the resolution? Acta Crystallogr. Sect. D 2013, 69, 1204-1214.

${ }^{6}$ McCoy, A.J.; Grosse-Kunstleve, R.W.; Adams, P.D.; Winn, M.D.; Storoni, L.C. \& Read, R.J. J. Appl. Cryst. 2007, 40, 658-674.

${ }^{7}$ Collaboration Computational Project, Number 4. The CCP4 Suite: programs for protein crystallography. Acta Crystallogr Sect. D 1994, 50, 760-763.

${ }^{8}$ Navaza, J. AMoRe: an automated package for molecular replacement. Acta Crystallogr. Sect. A 1994, 50, $157-163$.

${ }^{9}$ Blanc, E.; Roversi, P.; Vonrhein, C.; Flensburg, C.; Lea, S. M.; Bricogne, G. Refinement of severely incomplete structures with maximum likelihood in BUSTER/TNT. Acta Crystallogr., Sect. D: Biol. Crystallogr. 2004, 60, $2210-2221$.

${ }^{10}$ Emsley, P.; Lokhamp, B.; Scott, W.G.; Cowtan, K. Features and development of Coot. Acta Crystallogr., Sect. D: Biol. Crystallogr. 2010, 66, 486-501.

${ }^{11}$ Laskowski, R.A.; MacArthur, M.W.; Moss, D.S. \& Thornton, J.M. PROCHECK: a program to check the stereochemical quality of protein structures. J. Appl. Crystallogr. 1993, 26, 283-291. 
Crystallographic Statistics for Compound 16.

\begin{tabular}{|l|r|}
\hline Compound & \multicolumn{1}{|c|}{$\mathbf{1 6}$} \\
\hline Space group & $\mathrm{P} 2{ }_{1}{ }_{1}{ }_{1} 1$ \\
\hline Cell dimensions, $\AA$ & $54.5,81.7,93.0$ \\
\hline Resolution, $\AA$ & $92.97-2.10(2.21-2.10)$ \\
\hline Unique reflections & $24773(3434)$ \\
\hline Redundancy & $6.3(57)$ \\
\hline Completeness (\%) & $99.4(96.3)$ \\
\hline Rsym & $0.112(0.504)$ \\
\hline I/ $\sigma_{I}$ & $12.8(3.7)$ \\
\hline Refinement & \\
\hline Resolution, $\AA$ & $0.195(0.205)$ \\
\hline R-work & $0.235(0.208)$ \\
\hline R-free & 0.010 \\
\hline r.m.s.d. bond lengths, $\AA$ & 1.2 \\
\hline r.m.s.d. bond angles, ${ }^{\circ}$ & 99.2 \\
\hline Ramachandran favored and allowed ${ }^{*}(\%)$ & 0.8 \\
\hline Ramachandran disallowed ${ }^{*}(\%)$ & $7 J R A$ \\
\hline PDB ID & \\
\hline
\end{tabular}

Numbers in parentheses represent the highest resolution shell of data.

* As defined by Laskowski et al. ${ }^{11}$ 


\section{Analytical data for representative compounds}

HPLC trace of compound 7

Method A

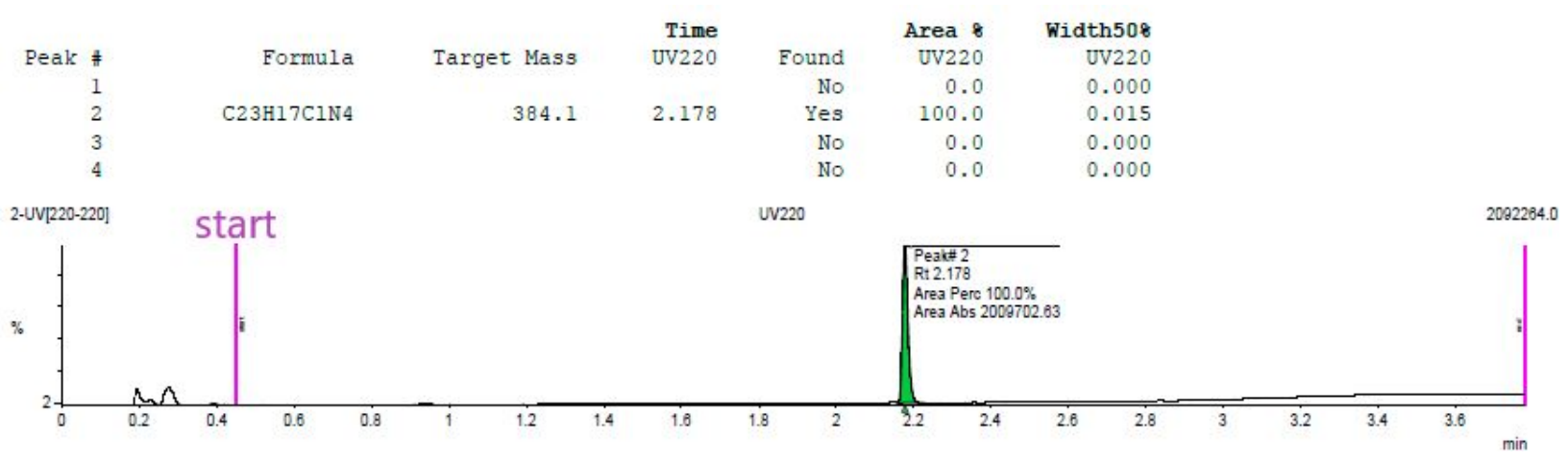

${ }^{1} \mathrm{H}-\mathrm{NMR}$ of compound 7

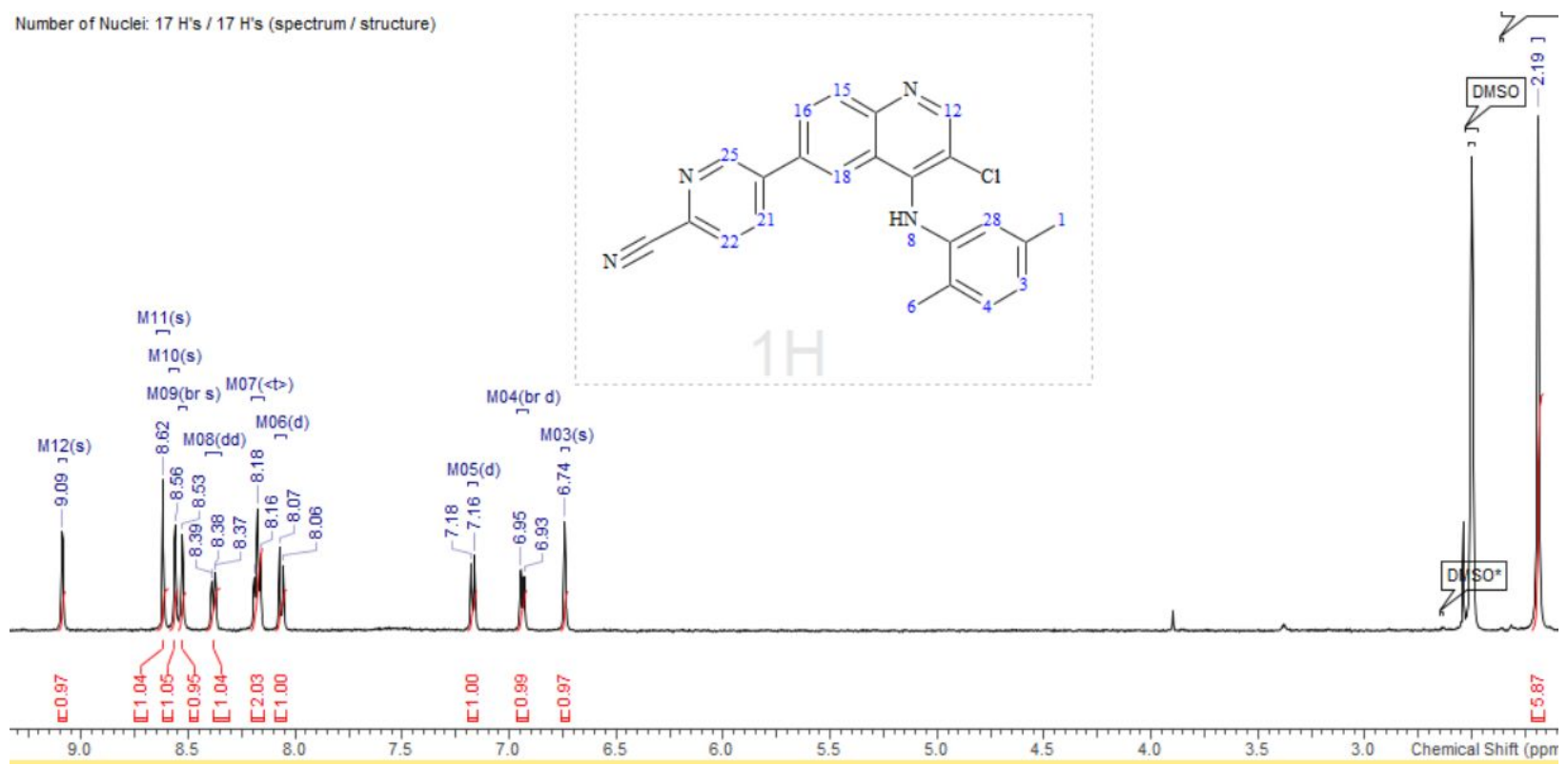

HPLC trace of compound $\mathbf{1 5}$

Method A 


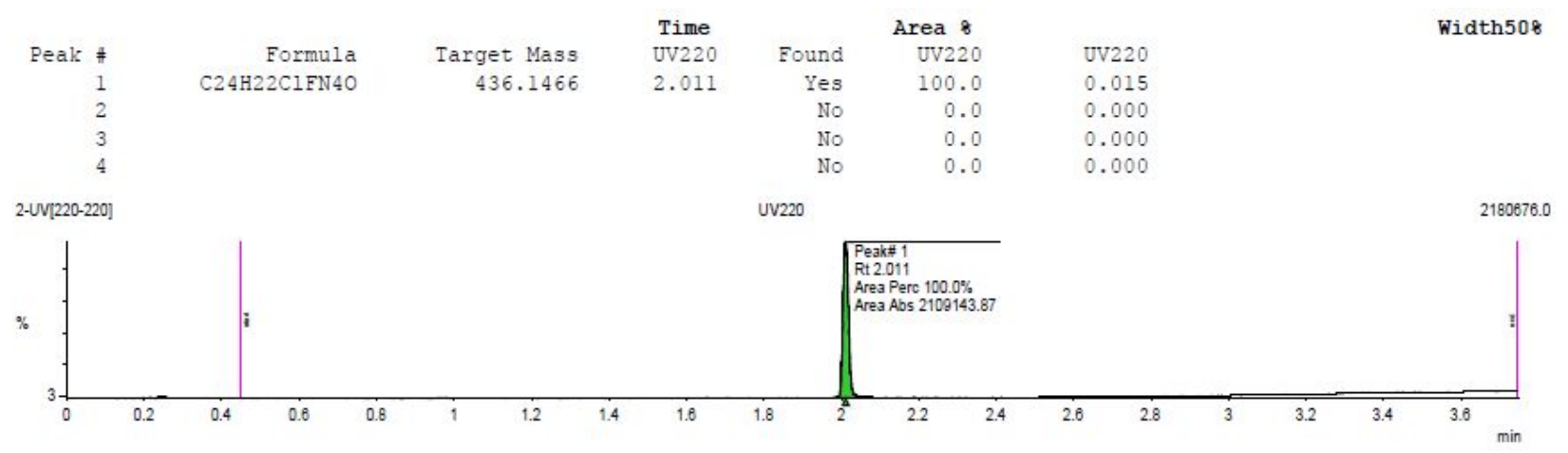

\section{${ }^{1} \mathrm{H}-\mathrm{NMR}$ of compound $\mathbf{1 5}$}

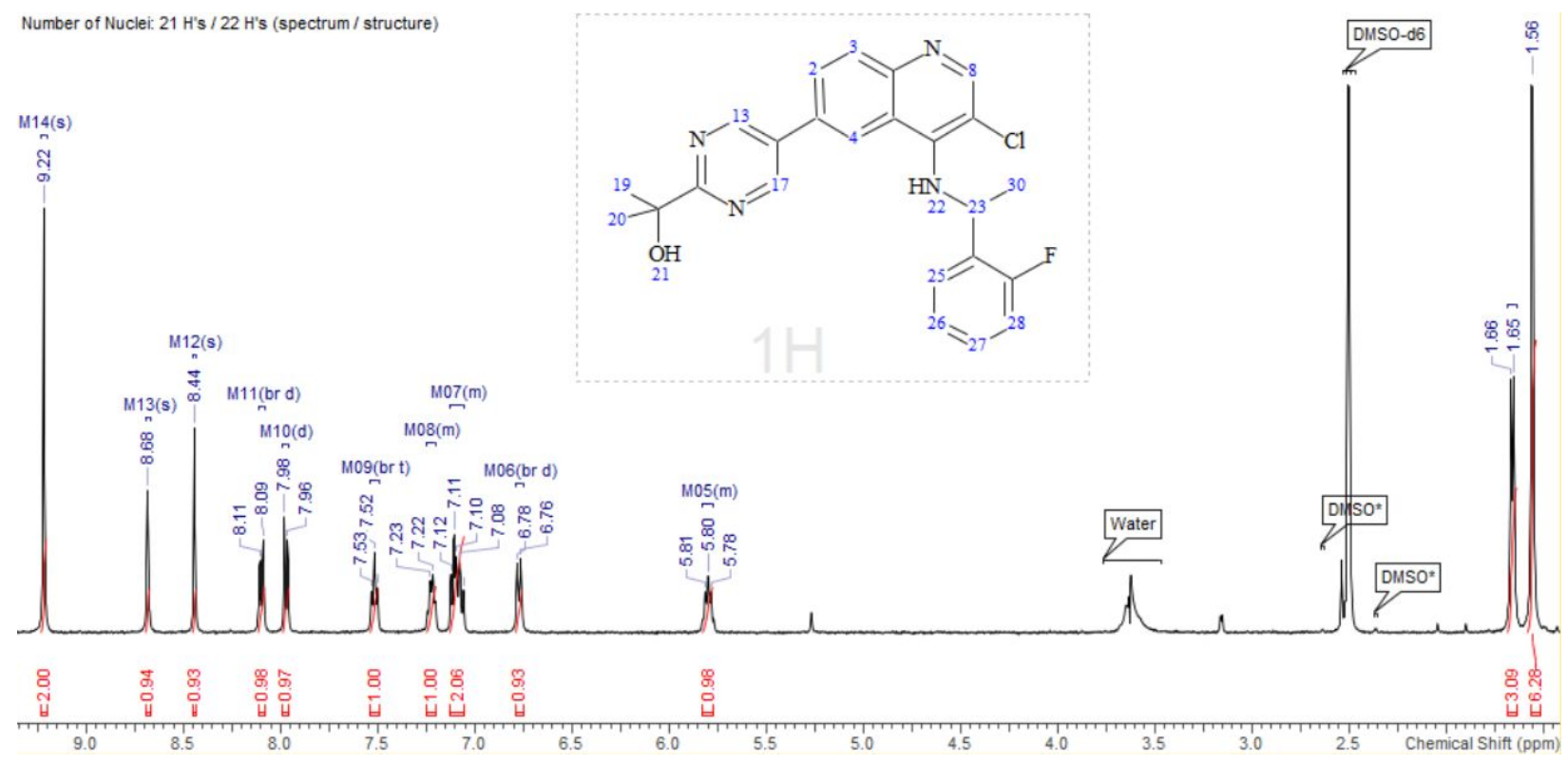

\section{HPLC trace of compound $\mathbf{2 9}$}

Method A

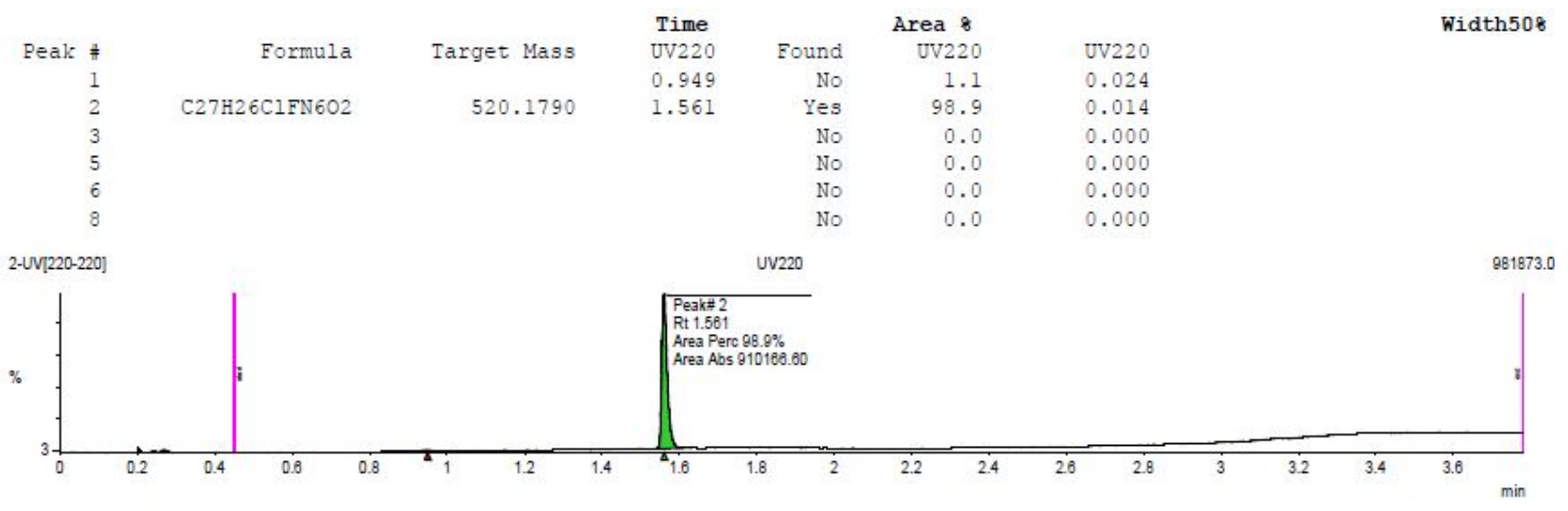

${ }^{1}$ H-NMR of compound 29 


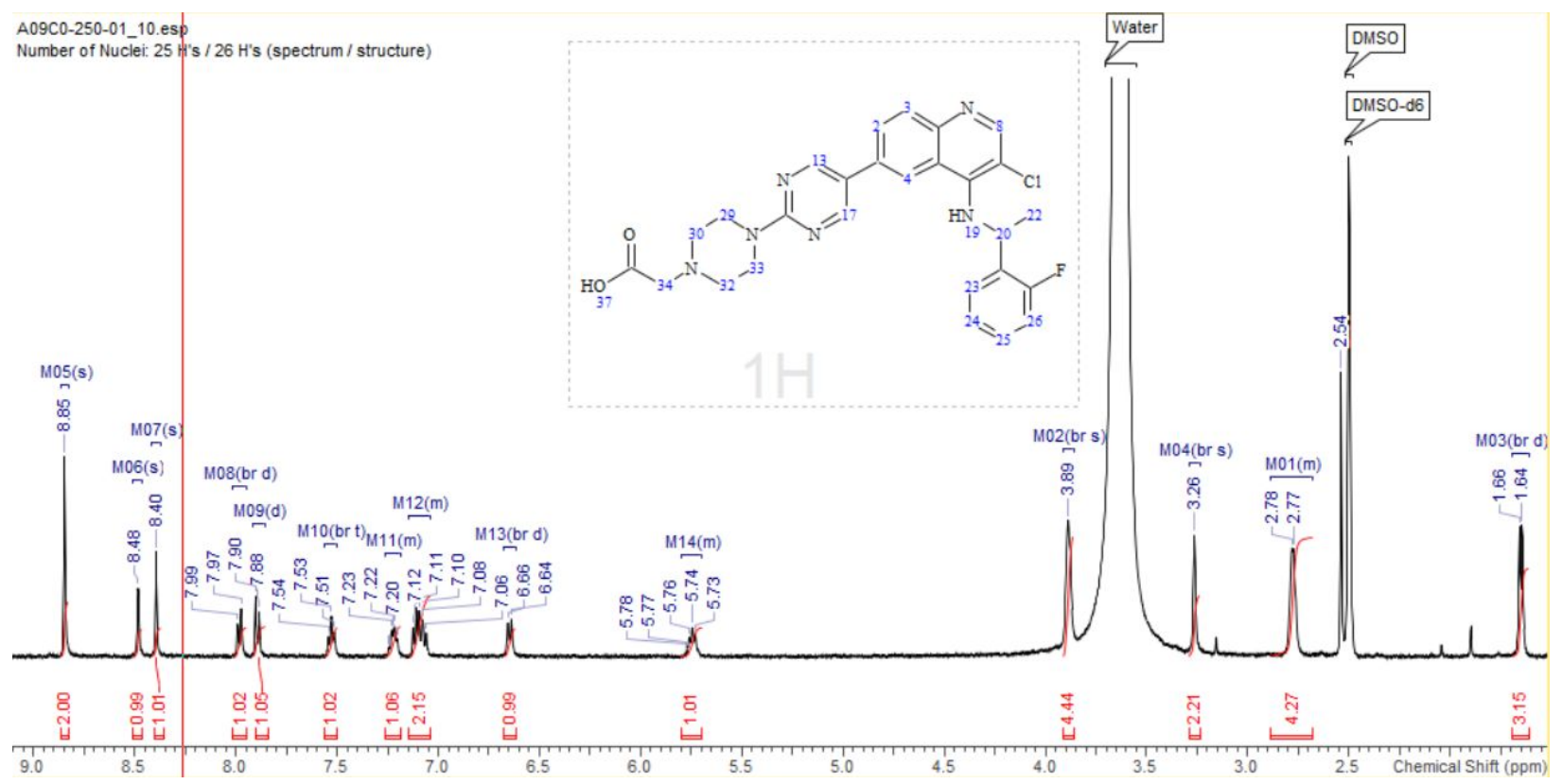

\section{HPLC trace of compound $\mathbf{3 5}$}

Method A

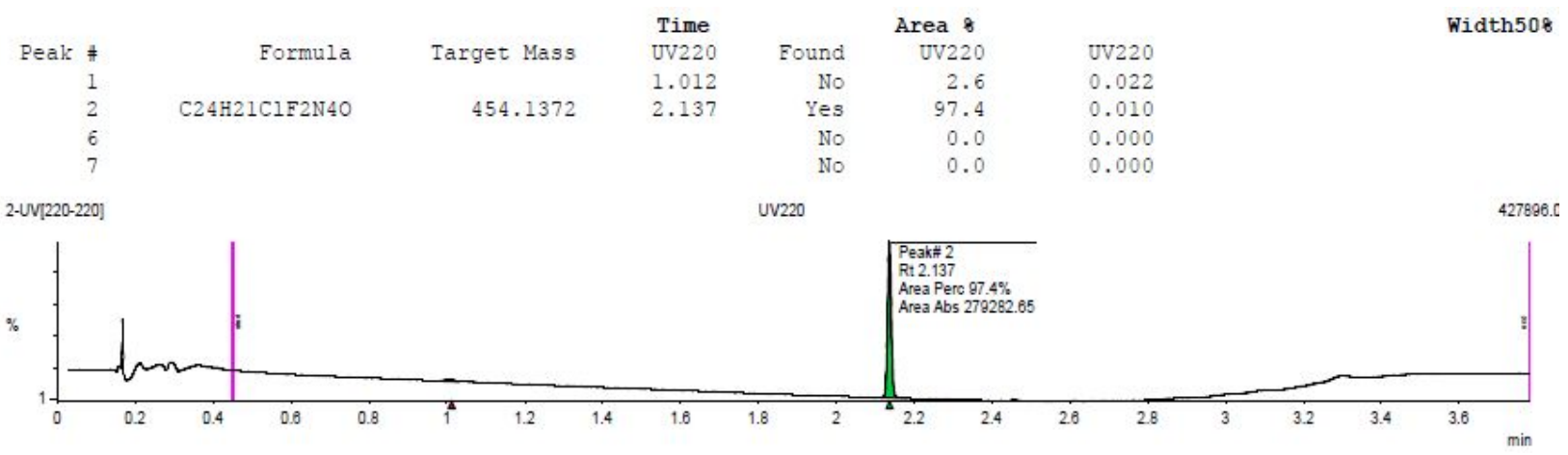

\section{${ }^{1} \mathrm{H}-\mathrm{NMR}$ of compound 35}




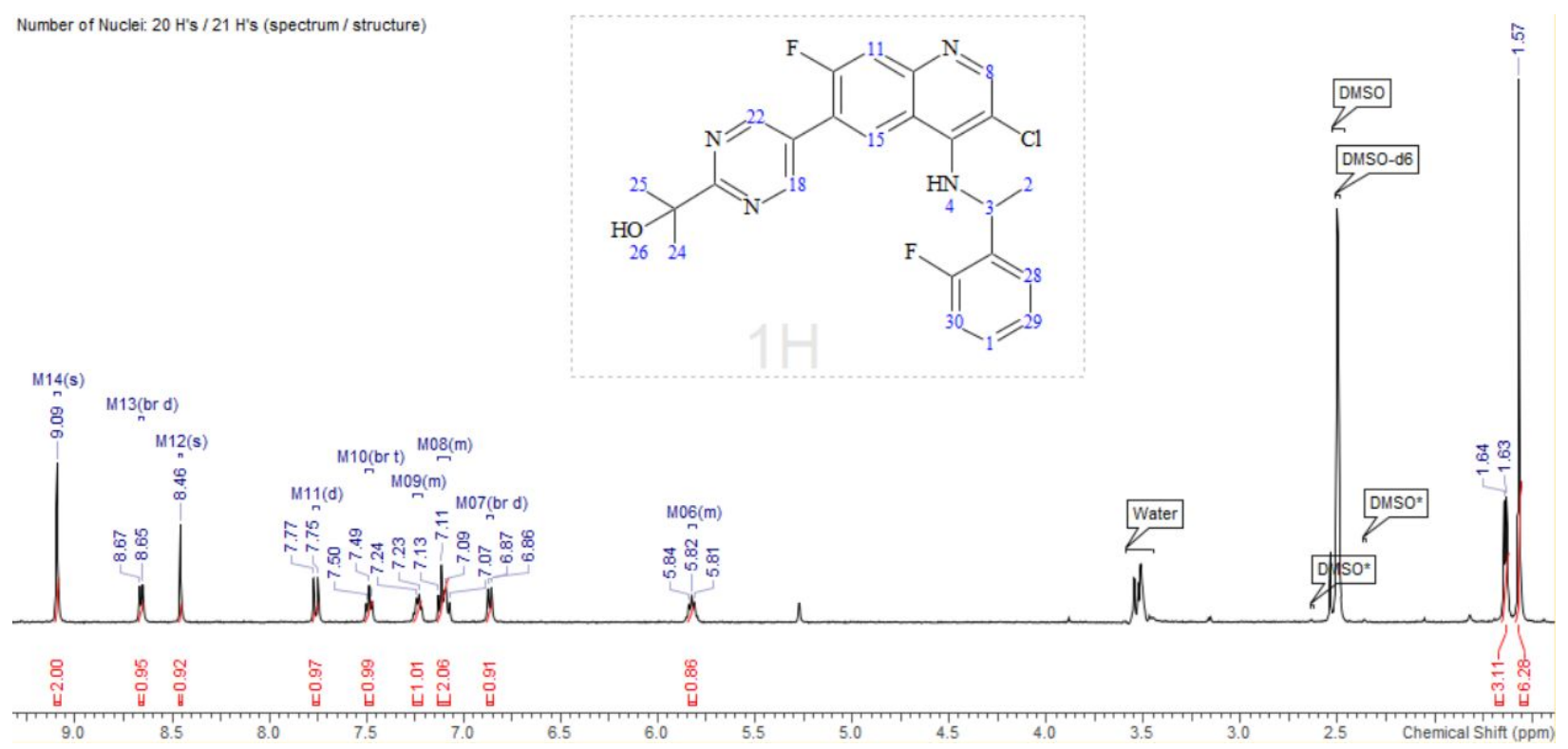

\section{HPLC trace of compound 39}

Method A

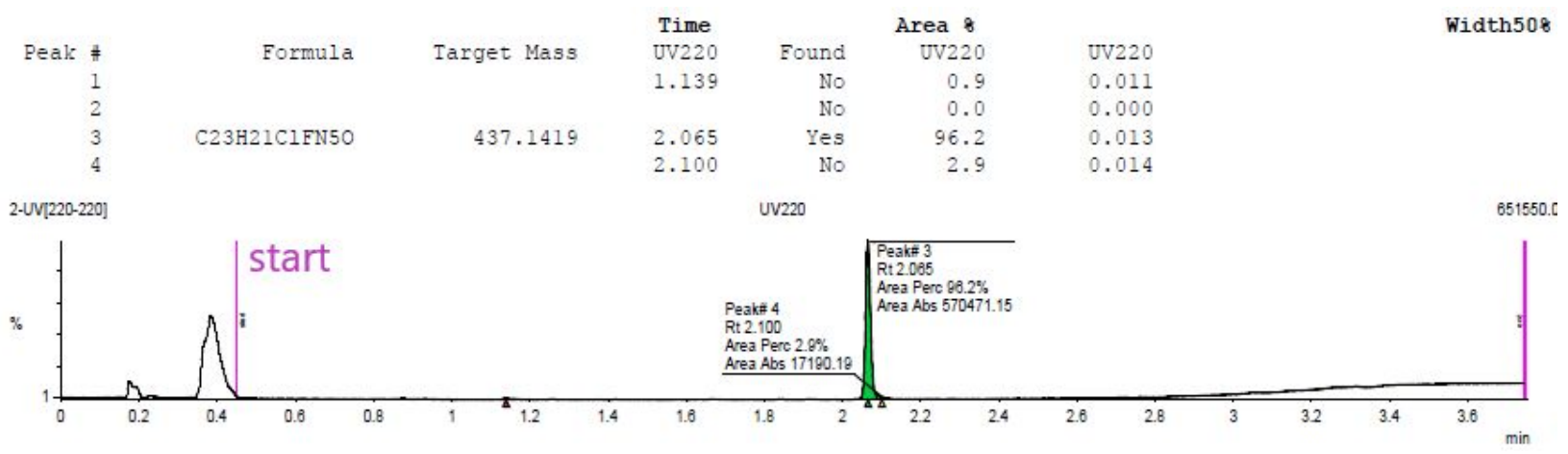

\section{${ }^{1} \mathrm{H}-\mathrm{NMR}$ of compound 39}




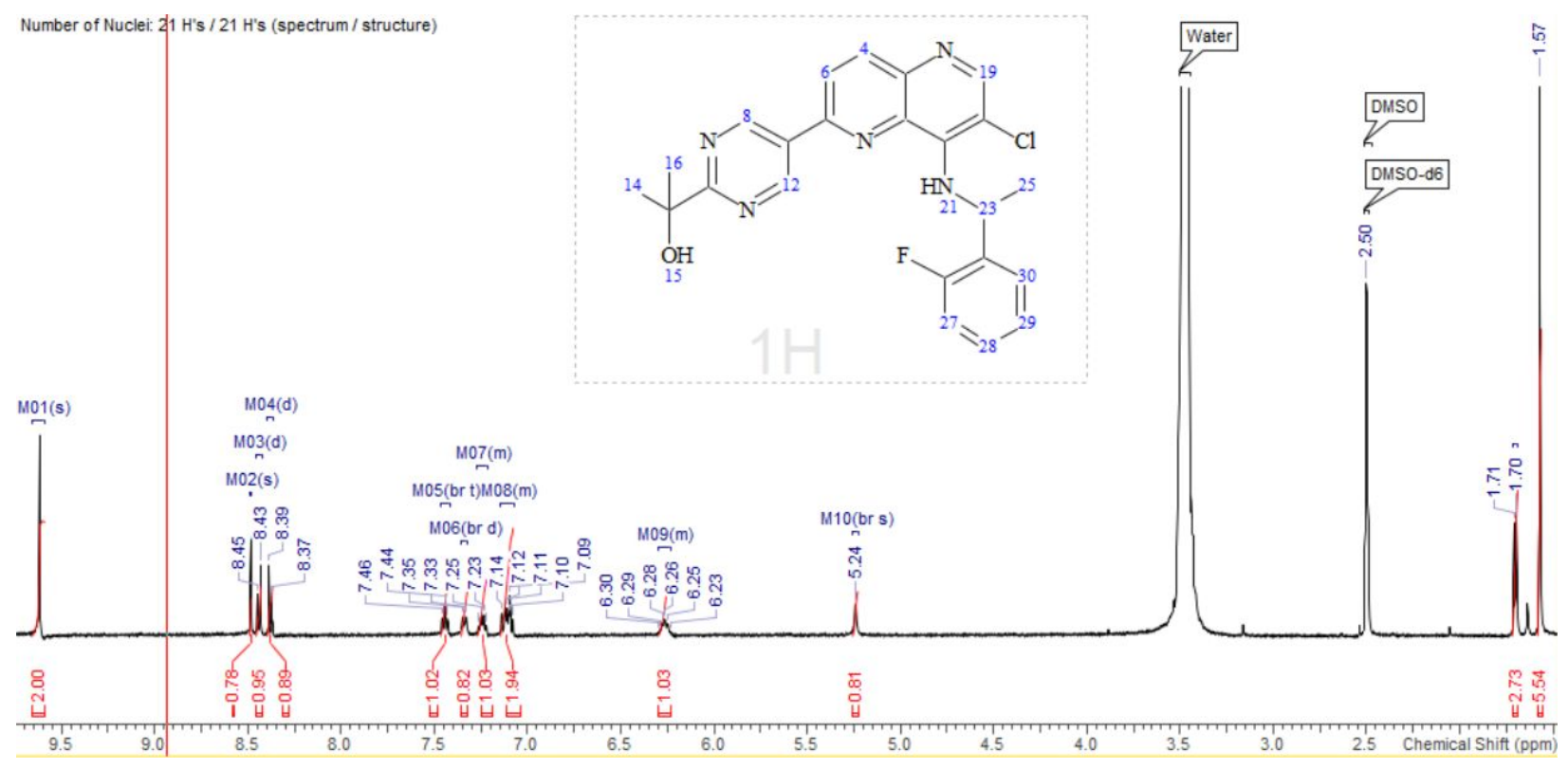

\section{HPLC trace of compound $\mathbf{4 2}$}

\section{Method D}

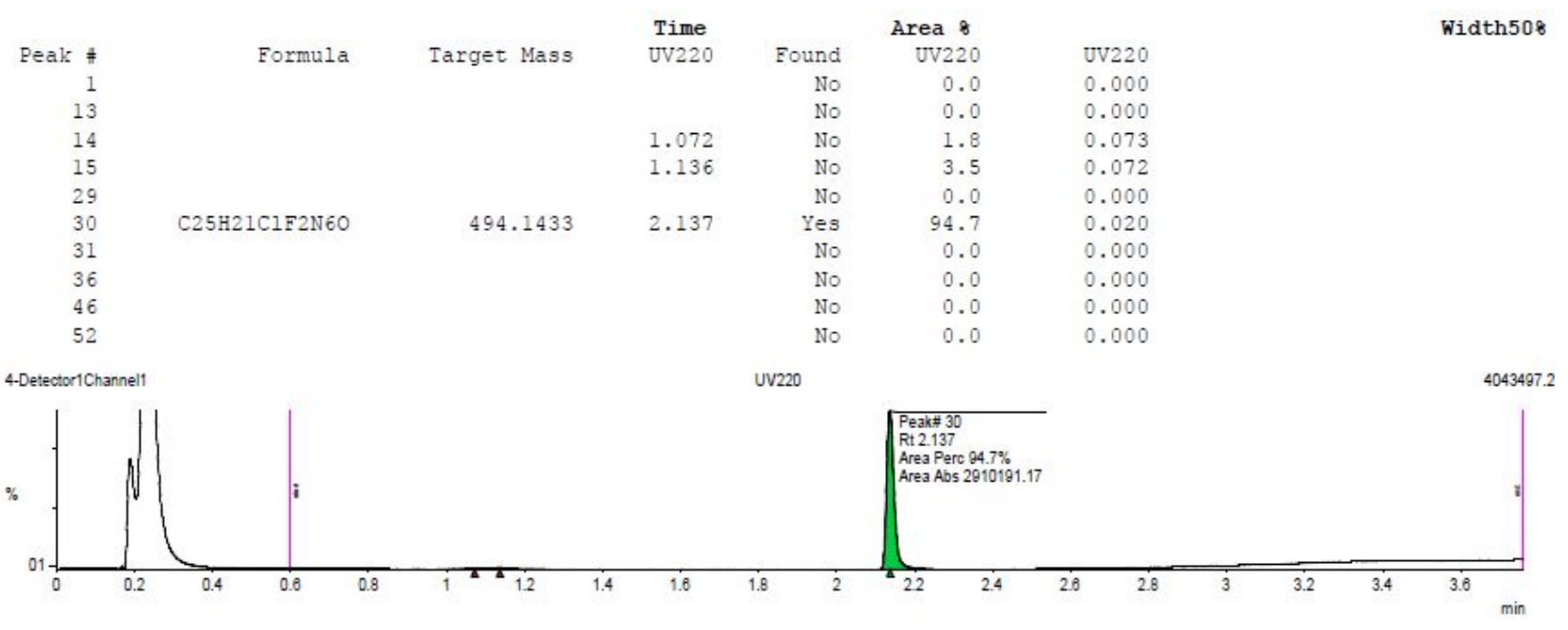

\section{${ }^{1} \mathrm{H}-\mathrm{NMR}$ of compound 42}




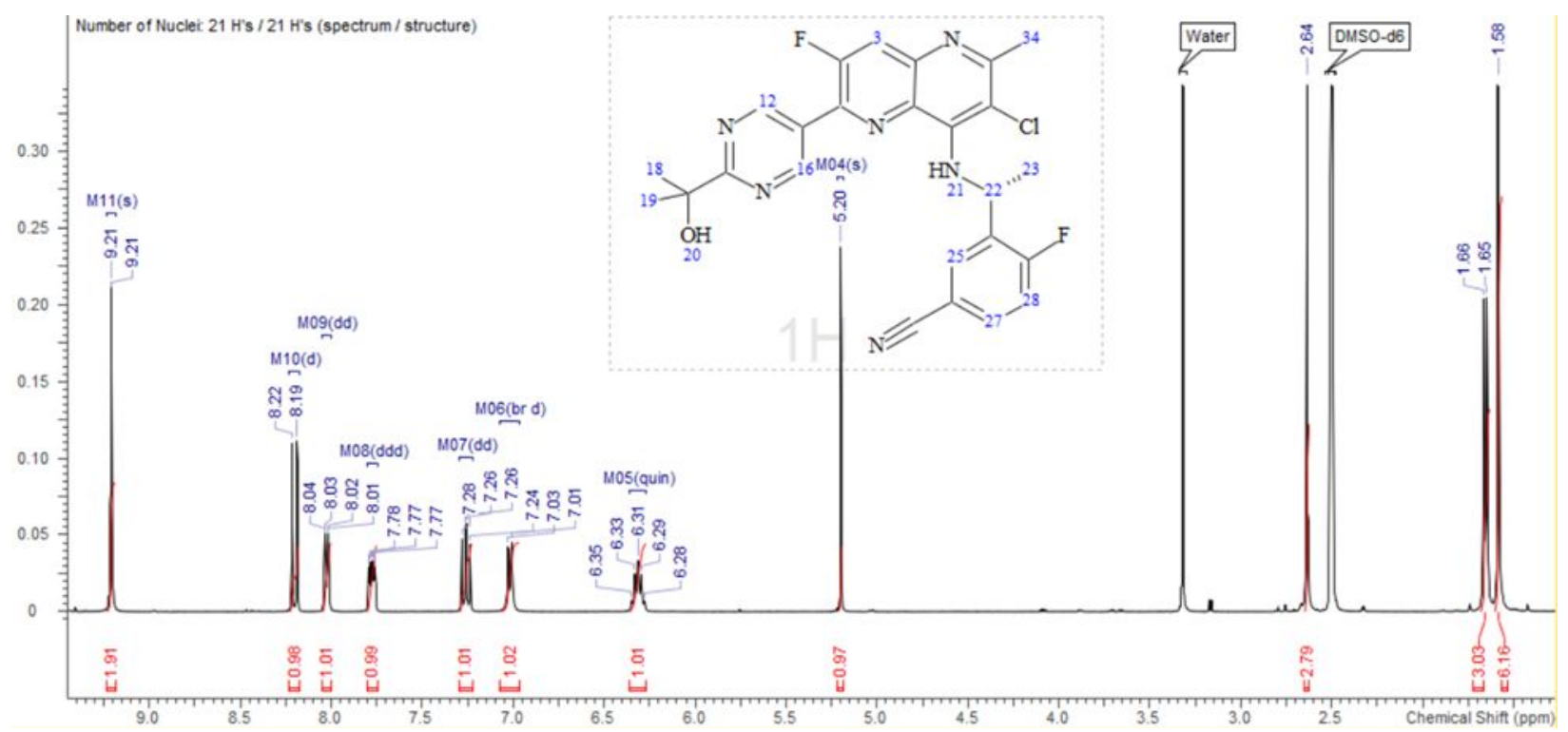

${ }^{13} \mathrm{C}-\mathrm{NMR}$ of compound 42

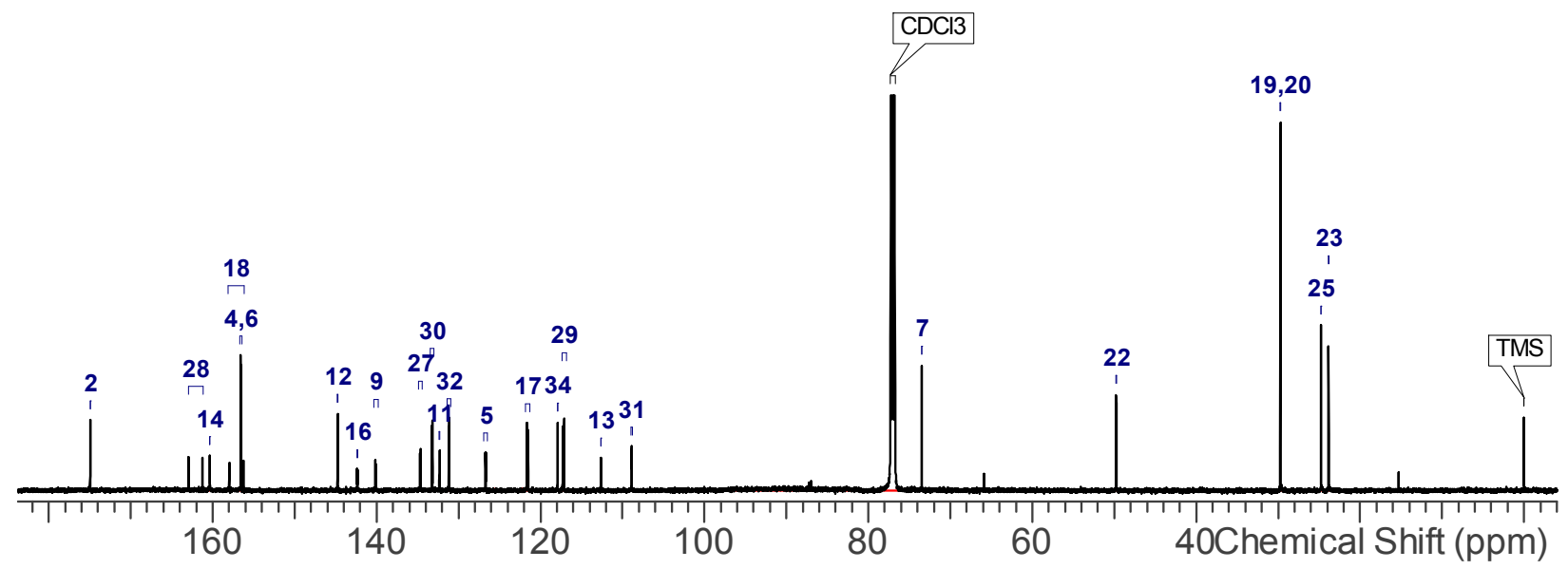

${ }^{13} \mathrm{C}$ NMR assignment of compound 42 


\begin{tabular}{|c|c|c|c|c|c|c|}
\hline Atom\# & $\mathrm{XHn}$ & H Shift & H Multiplicity & C Shift & C/X Multiplicity & X Shift \\
\hline 1,3 & $\mathrm{~N}$ & & & & $\mathrm{u}$ & 284.4 \\
\hline 2 & $\mathrm{C}$ & & & 174.9 & $\mathrm{~s}$ & \\
\hline 5 & $\mathrm{C}$ & & & 126.6 & $s$ & \\
\hline 6,4 & $\mathrm{CH}$ & 9.20 & $\mathrm{~s}$ & 156.5 & $\mathrm{~s}$ & \\
\hline 7 & $\mathrm{C}$ & & & 73.5 & $\mathrm{~s}$ & \\
\hline 9 & $\mathrm{C}$ & & & 140.1 & $\mathrm{~d}(15.41)$ & \\
\hline 11 & $\mathrm{C}$ & & & 132.3 & $\mathrm{~d}(2.20)$ & \\
\hline 12 & $\mathrm{C}$ & & & 144.7 & $\mathrm{~s}$ & \\
\hline 13 & $\mathrm{C}$ & & & 112.6 & $\mathrm{~s}$ & \\
\hline 14 & C & & & 160.4 & $\mathrm{~s}$ & \\
\hline 15 & $\mathrm{~N}$ & & & & $\mathrm{u}$ & 275.9 \\
\hline 16 & C & & & 142.3 & $d(8.80)$ & \\
\hline 17 & $\mathrm{CH}$ & 7.98 & $\mathrm{~d}(11.19)$ & 121.6 & $\mathrm{~m}$ & \\
\hline 18 & C & & & 157.1 & $\mathrm{~d}(264.09)$ & \\
\hline 19,20 & $\mathrm{CH} 3$ & 1.70 & $\mathrm{~s}$ & 29.7 & $\mathrm{~s}$ & \\
\hline 21 & $\mathrm{NH}$ & 6.44 & $\mathrm{~m}$ & & $\mathrm{u}$ & 92.0 \\
\hline 22 & $\mathrm{CH}$ & 6.34 & quin $(6.83,6.83,6.83,6.83)$ & 49.8 & $\mathrm{~s}$ & \\
\hline 23 & $\mathrm{CH} 3$ & 1.72 & $d(6.79)$ & & & \\
\hline 23 & $\mathrm{CH} 3$ & & & 23.8 & $\mathrm{u}$ & \\
\hline 25 & $\mathrm{CH} 3$ & 2.74 & $\mathrm{~s}$ & 24.8 & $\mathrm{~s}$ & \\
\hline 27 & $\mathrm{C}$ & & & 134.7 & $\mathrm{~d}(15.41)$ & \\
\hline 28 & $\mathrm{C}$ & & & 162.1 & $d(255.29)$ & \\
\hline 29 & $\mathrm{CH}$ & 7.07 & $\mathrm{t}(9.17,9.17)$ & 117.2 & $\mathrm{~d}(24.21)$ & \\
\hline 30 & $\mathrm{CH}$ & 7.51 & $\mathrm{~m}$ & 133.2 & $\mathrm{~d}(9.90)$ & \\
\hline 31 & $\mathrm{C}$ & & & 108.9 & $d(3.30)$ & \\
\hline 32 & $\mathrm{CH}$ & 7.57 & brd (6.60) & 131.2 & $d(5.50)$ & \\
\hline 34 & $\mathrm{C}$ & & & 117.9 & $\mathrm{~s}$ & \\
\hline
\end{tabular}

